\title{
Conditional earnings subsidies for low earners
}

\author{
Erwin Ooghe*
}

September, 2018

\begin{abstract}
Having low earnings is often not sufficient to be eligible for in-work tax credits. In the United Kingdom, New Zealand, and Ireland, for example, eligibility also requires that the number of hours worked is sufficiently high. Similarly, in France and Belgium the hourly wage rate must be sufficiently low. This paper provides a justification for such additional conditions. I analyze Pareto efficient redistribution from high to low ability individuals in a model where labour has several intensive margins. Besides labour hours, also labour effort - a vector of unpleasant, but productive features of labour - is an object of choice. Effort and ability determine the hourly wage rate. I find that conditional earnings subsidies for low earners are optimal: the earnings of low earners should be subsidized at the margin, but only if they earn more by working more hours at a sufficiently low wage rate.
\end{abstract}

JEL codes: H2, I3, J2

Keywords: optimal taxation, conditional earnings subsidies

*Erwin Ooghe, Department of Economics, KU Leuven, Naamsestraat, 69, 3000 Leuven; e-mail to erwin.ooghe@kuleuven.be. This paper has benefited from discussions with Rolf Aaberge, Spencer Bastani, Sören Blomquist, Robin Boadway, Bart Capéau, Vidar Christiansen, André Decoster, Stéphane Gauthier, Laurence Jacquet, Tobias König, Arnaud Lefranc, Sebastiaan Maes, Holger Lüthen, François Maniquet, David Margolis, Ronald Peeters, Andreas Peichl, Paolo Piacquadio, Erik Schokkaert, Kevin Spiritus, Alain Trannoy, Tom Truyts, Frank Vandenbroucke, Toon Vanheukelom, and Javier Vázquez-Grenno. I also thank audiences in Oslo, Brussels, Paris, Leuven, Mannheim, Louvain-la-Neuve, Barcelona, Berlin, Canazei, and Antwerpen for helpful comments. Finally, the comments of three anonymous referees were very helpful to revise the paper. 


\section{Motivation}

Welfare policies try to find - within budgetary limits - a good balance between two, often conflicting, goals: maintaining sufficiently high living standards and encouraging work. Over the past decades, encouraging work became a more prominent goal in many countries, witness the introduction or reinforcement of in-work tax credits (OECD, 2011). Such tax credits reduce the effective marginal tax rates and hence increase the incentives for low earners to work.

Having low earnings is necessary, but often not sufficient to be eligible for in-work tax credits. Eligibility may also require that either the number of hours worked is sufficiently high or the hourly wage rate is sufficiently low. I provide two examples of real world policies.

To get a Working Tax Credit in the United Kingdom you must have an annual income below $£ 13100$ (as a single between 25 and 59 years old and without children), but you must also work at least 30 hours a week 1 The base payment is currently up to $£ 1960$ per year. Other tax credits with minimal conditions on the number of hours worked are the In-Work Tax Credit in New Zealand and the Working Family Payment in Ireland $L^{2}$

To be eligible for a 'Werkbonus' (work bonus) in Belgium, your monthly gross earnings must be below $€ 2510$, but your gross wage rate must also be lower than $156 \%$ of the minimum wage 3 The bonus is currently up to $€ 2562$ per year (if you would work one year full-time as a laborer at the minimum wage). Another tax credit with a maximal condition on the wage rate was the 'Prime Pour l'Emploi' in France, which has been replaced by the 'Prime d'Activité' since 2016

One plausible justification for such additional conditions is to deter or even exclude mimickers, i.e., relatively able individuals who could become eligible by working fewer hours. Although deterring mimicking is a wellknown mechanism in the optimal tax literature, it has, to the best of my

\footnotetext{
${ }^{1}$ See the WTC webpage for the Working Tax Credit in the United Kingdom.

${ }^{2}$ See the IWTC webpage for the In-Work Tax Credit in New Zealand and the WFP webpage for the Working Family Payment in Ireland.

'See the WB webpage (in dutch, french, or german) for the 'Werkbonus' in Belgium.

${ }^{4}$ See the PPE wikipage for the 'Prime pour l'emploi' in France.
} 
knowledge, not been used to justify conditional earnings subsidies for low earners.

In the classical Mirrleesian model there simply is no room for subsidies (Mirrlees, 1971). In this model, unidimensional agents choose labour along the intensive margin and only earnings can be taxed by an inequality averse welfarist planner. These four assumptions together imply that the optimal marginal earnings tax rate is non-negative everywhere.

At least three assumptions turn out to be crucial. Indeed, negative marginal earnings tax rates can be optimal if agents are heterogeneous along multiple dimensions (Boadway et al., 2002, Fleurbaey and Maniquet, 2006, and Choné and Laroque, 2010), if labour is chosen along the extensive margin (Diamond, 1980, Saez, 2002, Choné and Laroque, 2011), or if the planner is either not inequality averse (Stiglitz, 1982, Werning, 2007) or not welfarist (Kanbur, Keen, and Tuomala, 1994, Kanbur, Pirttilä, and Tuomala, 2006, Pirttilä and Tuomala, 2004, Gerritsen, 2016, and Farhi and Gabaix, 2017).

This paper relaxes the remaining assumption. So, in this paper, unidimensional agents will choose labour along the intensive margin, but, for low earners, both hours worked and wages can be observed by an inequality averse welfarist planner 5

Now, if wages were observable and exogenous, then first-best lump-sum taxes on wages become feasible. However, empirical evidence shows that higher earnings taxes not only induce people to change hours worked, but also to move to jobs with lower wage rates and less disamenities (Gentry and Hubbard, 2004, Blomquist and Selin, 2010, Powell, 2010, and Powell and Shan, 2012). In other words, wages are endogenous, i.e., chosen by individuals, and must be modelled accordingly 6

To model wages in an endogenous way, labour is assumed to have multiple dimensions, called labour hours and labour effort. Similar to labour hours, labour effort is a vector of unpleasant, but productive features of

\footnotetext{
${ }^{5}$ To attribute the optimality of (conditional) earnings subsidies to the observability of wages and hours, I must relax observability only. Relaxing other assumptions on top is likely to reinforce the possibility of earnings subsidies.

${ }^{6}$ This feature not only makes the current paper more realistic, but also different from the optimal wage tax literature with observable and exogenous wages (see, e.g., Allingham, 1975, Wagstaff, 1975, Kesselman, 1976, Helpman and Sadka, 1978, and Blomquist, 1981).
} 
labour. Effort - together with ability - will determine the hourly wage rate. To sum up: because effort is chosen, wages are endogenous; and because the determinants of wages - ability and effort - are not observable (by assumption), first-best taxation remains impossible.

In this model, there are several ways in which low earners can earn more, e.g., by working more hours or working at a higher wage rate (by exerting more effort). The optimal fiscal treatment of the different margins depends on the preferences of mimickers, being, higher ability individuals that pretend to have a lower ability type by choosing to earn less. As a general rule, if a certain margin is preferred relatively more by mimickers, then that margin will be discouraged, and thus taxed; and if a certain margin is preferred relatively less by mimickers, then that margin will be encouraged, and thus subsidized. Such a fiscal treatment deters mimicking, which allows to relax the self-selection constraint of the second-best tax problem, and, ultimately, to improve redistribution (see, e.g., Boadway, 2012, chapter 4).

Because the optimal fiscal treatment of the different margins crucially depends on the (mimicking) behavior of agents with different abilities, I have to study the impact of ability on labour choices. To add structure to the problem, I introduce single-crossingness conditions. However, with several margins, the number of combinations of single-crossingness conditions is potentially large. Yet, I argue that only two combinations are reasonable. These two combinations differ in one respect only, i.e., whether individuals with a higher ability type need to be compensated less (case 1) or more (case 2) in terms of extra consumption for a small increase in hours worked, ceteris paribus.

The main result of the paper consists of three conditional results.

First, the earnings-conditional marginal tax rate on hours worked must be negative for low earners. In other words, if two individuals have the same low earnings, then the one who works more hours (at a lower wage rate, necessarily) will pay less taxes $]^{7}$

Second, the hours-conditional marginal tax rate on wages should be pos-

\footnotetext{
${ }^{7}$ Because working more hours and earning the same income is only possible by working at a lower wage rate, an earnings-conditional subsidy on hours worked is, by definition, equivalent to an earnings-conditional tax on the wage rate.
} 
itive for low earners. So, earning more by choosing a job with a higher wage rate (and the same hours worked) will be taxed for low earners.

Third, the wage-conditional marginal tax rate on hours worked can be positive or negative for low earners, depending on whether case 1 or 2 applies. So, earning more by choosing to work more hours (at the same wage rate) will either be taxed (case 1) or subsidized (case 2) for low earners.

Four papers, two theoretical ones and two empirical ones, are closely related to the current paper and are therefore discussed in more detail.

Blomquist (1984) employs a model where unidimensional agents choose hours worked and educational effort along the intensive margin. Educational effort and ability together define wages. Although the set-up is very similar, the paper focuses on comparing the performance of linear wage taxation versus linear earnings taxation and finds that wage taxation is superior.

Beaudry, Blackorby, and Szalay (2009) analyze wage-contingent earnings taxation, i.e., taxes are a non-linear function of earnings and wages 8 Although the focus of this paper is very similar, the underlying model is quite different. They also introduce wage observability, but consider multidimensional agents who allocate a fixed number of working hours over two sectors, a formal market sector and an informal household sector. They find that it is optimal to subsidize earnings below a cutoff wage rate and tax earnings above that cutoff.

Blundell and Shephard (2012) analyze the Working Families' Tax Credit (WFTC) reform in the United Kingdom. This reform increased generosity, but also introduced a minimal number of hours worked as an eligibility condition. If optimally set, the potential welfare gain from using hourscontingent tax credits for lone parents is equivalent to a increase of $2.5 \%$ in current expenditures. Although non-trivial, the paper shows that if hours are misreported unwillingly (measurement error) or willingly (to increase utility), then these welfare gains decrease with the size of the measurement error or the utility cost of misreporting hours. These simulations stress the potential importance of misreporting, but do not say anything about

\footnotetext{
${ }^{8}$ It is worth mentioning that Nishimura (2004) and Tillmann (2005) study the use of hours-contingent taxation - taxes are a non-linear function of earnings and hours-, but to implement fair (i.e., envy-free) allocations.
} 
whether misreporting occurs in reality.

Cahuc and Carcillo (2014) analyze the detaxation of overtime in France and show that manipulating normal and overtime hours occurs only among highly qualified employees whose hours are hard to verify. In France, these employees belong to teaching and the scientific professions, media professions, arts and entertainment, administrative and commercial managers of firms, engineers, professionals, foremen and supervisors.9 The main message is that conditional earnings subsidies should be restricted to jobs whose hours worked can be easily verified. Because earnings are typically lower in such jobs, I will assume observability for low earners only.

The remainder of the paper proceeds as follows. Section 2 introduces the model. Section 3 analyzes the utility-maximizing choices of individuals with different ability levels. Section 4 studies optimal taxation in case only earnings are observable and in case hours and wages are observable for low earners. I find that earnings subsidies are not optimal if only earnings are observable, but conditional earnings subsidies can be optimal if hours and wages are observable for low earners. Both results together show that the observability of hours and wages is crucial to justify subsidies (and not the feature of the model that labour has several intensive margins). A final section 5 concludes.

\section{The model}

In this section, I first introduce (in subsection 2.1) the fundamentals that drive choices: preferences, market environment, technology, ability, and taxation. As the main aim of the paper is to analyze optimal taxation if hours and wages are observable (for low earners), I also add a brief discussion on tax schemes that depend on hours and wages (subsection 2.2). Moreover, I discuss (in subsection 2.3) how to express preferences over jobs (a combination of hours and wages) instead of preferences over labour (a combination of hours and effort).

\footnotetext{
${ }^{9}$ Cahuc and Carcillo (2014) only look at employees, but it is reasonable to assume that the self-employed should be added to the group whose hours are hard to verify.
} 


\subsection{Preliminaries}

Labour has several margins. It collects labour hours (a scalar) and labour effort (a vector), summarized as $(h, \mathbf{e})$. Labour effort consists of unpleasant, but productive features of labour, other than hours worked.

The choice of labour - i.e., hours and effort-depends on preferences, market environment, technology, ability, and taxation.

Preferences are the same for all individuals and can be represented by a twice differentiable and strictly quasi-concave utility function $u:(c, h, \mathbf{e}) \mapsto$ $u(c, h, \mathbf{e})$ that strictly increases in consumption (net earnings) and strictly decreases in hours and effort.

Market environment and technology define how ability, denoted $\theta$, and labour translates into gross earnings. In a perfectly competitive labour market with a production technology that is linear in ability and hours workedstrong, yet common assumptions in the optimal tax literature - gross earnings $y$ are equal to $\theta f(\mathbf{e}) h$, with $f$ a differentiable, strictly increasing, and concave function. The product $\theta f(\mathbf{e})$ measures the hourly wage rate, which is denoted by $w$.

Taxation drives a wedge between gross earnings and net earnings, i.e., the $\operatorname{tax} t$ is equal to $y-c$. If only gross earnings are observable (as in subsections 3.2 and 4.2 later on), then the tax can only be a non-linear function of gross earnings, say, $t=T(y)$. If the components of gross earnings-wages and hours - are observable for low earners (as in subsections 3.3 and 4.3), then the tax can be a non-linear function of these components, say, $t=T(h, w){ }^{10}$ Taxes of the form $t=T(h, w)$ are unusual in the optimal tax literature and require therefore some additional explanation.

\subsection{Taxation and conditional tax credits}

Taxes of the form $t=T(h, w)$ reduce to a classical non-linear earnings tax if $T(h, w)=\phi(w h)$ holds everywhere. But new possibilities arise. For

\footnotetext{
${ }^{10}$ Because $y=w h$ holds by definition, each of the three pairs $(h, w),(y, w)$, and $(h, y)$ contains the same information and can form the basis of taxation. I choose hours and wages as the tax base. As mentioned before, Beaudry, Blackorby, and Szalay (2009) study wage-contingent earnings taxation, i.e., $t=T(w, y)$; and Nishimura (2004) and Tillmann (2005) study hours-contingent earnings taxation, i.e., $t=T(h, y)$.
} 
example, a conditional tax credit, say $C(h, w)$, would change the tax scheme to $T(h, w)=\phi(w h)-C(h, w)$. To illustrate this possibility, I again use (stylized versions of) the two real world examples that I introduced before.

The Working Tax Credit (United Kingdom) is an earnings tax credit conditional on working a minimal amount of hours, say, $\underline{h}$. It is thus defined as $C(h, w)=A(w h)$ if $h \geq \underline{h}$ and $C(h, w)=0$ otherwise, with $A>0$ over some earnings range.

The 'Werkbonus' (Belgium) is defined as $C(h, w)=A(w) h$ with $A$ linearly decreasing in the wage rate for wages below $156 \%$ of the minimum wage. In more detail, if $\underline{w}$ denotes the minimum wage, then $A(w) \approx$ $\mu(1.56 \underline{w}-w)$ if $\underline{w} \leq w \leq 1.56 \underline{w}$ and $A(w)=0$ otherwise 11

Using the general form $t=T(h, w)$ again, the signs of the derivatives $T_{h}^{\prime}$ and $T_{w}^{\prime}$ define how the different margins are treated fiscally. For example, subsidizing hours worked at the margin - a 'wage-conditional' hour subsidy - corresponds with $T_{h}^{\prime}(h, w)<0$. And taxing the wage rate at the margin - an 'hours-conditional' wage tax-occurs if $T_{w}^{\prime}(h, w)>0$. Using the definition $w=y / h$ and differentiating $T(h, y / h)$ with respect to $h$ one gets $T_{h}^{\prime}(h, w)-T_{w}^{\prime}(h, w) w / h$. The sign of this expression informs us about the fiscal treatment of hours for individuals who earn the same income. So, if the expression is negative, for example, then individuals who work more hours at a lower wage rate (for the same gross earnings) pay less taxes. I call a negative sign therefore an 'earnings-conditional' hour subsidy $\left[{ }^{12}\right.$ Table 1 summarizes the fiscal treatment of the different margins, ${ }^{13}$

As the stylized version of the 'Werkbonus' (Belgium) has a rather smooth formula over the relevant wage range, it is easy to check these derivatives. Because the (standard) marginal earnings tax rate is high for low earners in Belgium it turns out that conditional on wages, hours are taxed at the

\footnotetext{
${ }^{11}$ The parameter $\mu>0$ is roughly equal to 0.22 and 0.24 for white- and blue-collar workers.

${ }^{12}$ Conditional on earnings, hours and wages are inversely related. So, we could also have called an 'earnings-conditional' hour subsidy an 'earnings-conditional' wage tax.

${ }^{13}$ Note that these conditional marginal tax rates are linked. For example, a "wageconditional' hour subsidy combined with an 'hour-conditional' wage tax must, by definition, lead to an 'earnings-conditional' hour subsidy (because $T_{h}^{\prime}(h, w)-T_{w}^{\prime}(h, w) w / h$ is indeed negative under these conditions).
} 
Table 1: Three conditional marginal taxes

\begin{tabular}{|c|c|c|}
\hline margin & taxed at the margin if & subsidized at the margin if \\
\hline $\mid w$ & $T_{h}^{\prime}(h, w)>0$ & $T_{h}^{\prime}(h, w)<0$ \\
\hline$w$ & $T_{w}^{\prime}(h, w)>0$ & $T_{w}^{\prime}(h, w)<0$ \\
\hline$h$ & $T_{h}^{\prime}(h, w)-T_{w}^{\prime}(h, w) w / h>0$ & $T_{h}^{\prime}(h, w)-T_{w}^{\prime}(h, w) w / h<0$ \\
\hline
\end{tabular}

margin $\left(T_{h}^{\prime}(h, w)>0\right)$, conditional on hours, wages are taxed at the margin $\left(T_{w}^{\prime}(h, w)>0\right)$, and conditional on earnings, hours are subsidized at the $\operatorname{margin}\left(T_{h}^{\prime}(h, w)-T_{w}^{\prime}(h, w) w / h<0\right){ }^{14}$

\subsection{From labour to jobs}

Because taxes can be a function of hours and wages, it is more convenient to focus on jobs (a combination of hours and wages) rather than on labour (a combination of hours and effort). I briefly discuss therefore how preferences can be expressed over jobs instead of labour.

Let $(h, w)$ denote a job. Because the same job can be done with different vectors of effort, the solution to the problem

$$
\max _{\mathbf{e} \geq \mathbf{0}} u(c, h, \mathbf{e}) \text { such that } \theta f(\mathbf{e}) \geq w,
$$

gives us the best amount of effort, denoted $\mathbf{e}(c, h, w, \theta)$, that an individual with ability type $\theta$ chooses to do the specified job.

\footnotetext{
${ }^{14}$ For wages in the relevant range $(\underline{w} \leq w \leq 1.56 \underline{w})$, taxes are
}

$$
T(h, w)=\phi(w h)-\mu(1.56 \underline{w}-w) h .
$$

Given a sufficiently high (standard) marginal tax rate for low earners in Belgium (satisfying $\phi^{\prime}(w h)>0.13$ for sure) and given $\mu \approx 0.23>0$, marginal taxes become

$$
\begin{aligned}
T_{h}^{\prime}(h, w) & =\phi^{\prime}(w h) w-\mu(1.56 \underline{w}-w) \\
& \approx\left(\phi^{\prime}(w h)+0.23\right) w-0.36 \underline{w}>0, \\
T_{w}^{\prime}(h, w) & =\left(\phi^{\prime}(w h)+\mu\right) h>0,
\end{aligned}
$$

and

$$
T_{h}^{\prime}(h, w)-T_{w}^{\prime}(h, w) w / h=-1.56 \mu \underline{w}<0 .
$$


If I plug in the solution in the utility function, then utility becomes a function of net earnings, jobs, and ability. Proposition 1 summarizes. Unless stated otherwise, proofs can be found in the appendix.

Proposition 1. The utility function $U$, defined as

$$
U:(c, h, w, \theta) \mapsto U(c, h, w, \theta)=u(c, h, \mathbf{e}(c, h, w, \theta)),
$$

is strictly increasing in consumption (net earnings), strictly decreasing in hours and wages, and strictly increasing in ability.

\section{Job choice}

In this section, I analyze job choice. I first study the problem of job choice conditional on earnings (subsection 3.1), which will turn out to be of general relevance later on. Afterwards I look at job choice if only earnings can be taxed (subsection 3.2) and if hours and wages can be taxed (subsection 3.3). In each of these three subsections, I illustrate how single-crossingness conditions define how ability affects choices. A more detailed discussion of the different single-crossingness conditions is postponed to the next section.

\subsection{Job choice conditional on earnings}

Given an amount of net earnings $c$, what is the best job $(h, w)$ according to an individual with ability type $\theta$ to obtain a level of gross earnings $y$ ? The utility-maximizing job, conditional on earnings, follows from

$$
\max _{h, w \geq 0} U(c, h, w, \theta) \text { such that } w h \geq y .
$$

The first-order condition can be written as

$$
M W H(c, h, w, \theta)=-\frac{w}{h},
$$

where $M W H$ is the marginal rate of substitution of wages for hours ${ }^{15}$

Only the left-hand side of the first-order condition (4) depends on ability. So, it informs us how changes in ability affect choices. For example, if

\footnotetext{
${ }^{15}$ It tells us how much the wage (and thus effort) should decrease to compensate for a small increase in hours worked and is defined as $M W H(c, h, w, \theta)=-\frac{U_{h}^{\prime}(c, h, w, \theta)}{U_{w}^{\prime}(c, h, w, \theta)}<0$.
} 
the single-crossingness condition $M W H_{\theta}^{\prime}<0$ holds, then higher ability individuals must be compensated more in terms of wages for a small increase in hours worked. As a consequence, higher ability individuals would always choose less hours and a higher wage rate to reach the same gross earnings as an individual with a lower ability level.

\subsection{Job choice if only earnings can be taxed}

If only earnings can be taxed, then the utility-maximizing job solves

$$
\max _{h, w \geq 0} U(c, h, w, \theta) \text { such that } c \leq w h-T(w h) .
$$

This problem can be split up in two steps.

First, the solution to the earnings-conditional problem (3), say, $\hat{H}(c, y, \theta)$ and $\hat{W}(c, y, \theta)$, can be plugged in in the utility function $U$. As such, utility becomes indirectly expressed as a function of net earnings, gross earnings, and type. Proposition 2 summarizes.

Proposition 2. The utility function $V$, defined as

$$
V:(c, y, \theta) \mapsto V(c, y, \theta)=U(c, \hat{H}(c, y, \theta), \hat{W}(c, y, \theta), \theta),
$$

is strictly increasing in consumption (net earnings), strictly decreasing in gross earnings, and strictly increasing in ability.

Second, problem (5) can be solved by maximizing utility, according to $V$, over earnings, i.e.,

$$
\max _{c, y \geq 0} V(c, y, \theta) \text { such that } c \leq y-T(y) .
$$

The first-order condition can be expressed as

$$
\operatorname{MCY}(c, y, \theta)=1-T^{\prime}(y)
$$

where $M C Y$ is the marginal rate of substitution of net for gross earnings ${ }^{16}$

Equation (8) informs us again how changes in ability affect choices. The usual Spence-Mirrlees condition imposes that higher ability types need to

\footnotetext{
${ }^{16}$ It tells us how much net earnings should increase to compensate for a small increase in gross earnings and is defined as $M C Y(c, y, \theta)=-\frac{V_{y}^{\prime}(c, y, \theta)}{V_{c}^{\prime}(c, y, \theta)}>0$.
} 
be compensated less in terms of net earnings for a small increase in gross earnings, i.e., $M C Y_{\theta}^{\prime}<0$. This would imply that higher ability individuals always choose higher gross earnings.

\subsection{Job choice if hours and wages can be taxed}

If hours and wages can be taxed, then the utility-maximizing job solves

$$
\max _{h, w \geq 0} U(c, h, w, \theta) \text { such that } c \leq w h-T(w, h) .
$$

The first-order conditions can be expressed as

$$
\begin{aligned}
\operatorname{MCH}(c, h, w, \theta) & =w-T_{h}^{\prime}(h, w), \\
M C W(c, h, w, \theta) & =h-T_{w}^{\prime}(h, w),
\end{aligned}
$$

where $M C H$ and $M C W$ are the marginal rates of substitution of consumption for either hours or wages. ${ }^{17}$

Single-crossingness conditions can again give direction to the choices of individuals with different abilities. If, for example, the single-crossingness condition $M C W_{\theta}^{\prime}<0$ would hold, then higher ability types always need to be compensated less for a small increase in wages. As a consequence, they would always choose higher wages for a given number of labour hours. Similarly, if the condition $M C H_{\theta}^{\prime}>0$ were true, then higher ability types always need to be compensated more for a small increase in hours worked. As a consequence, they would always choose to work less hours, for a given wage rate.

\section{Optimal taxation}

To characterize optimal taxation in the simplest possible way, I follow Stiglitz (1982) and introduce two ability types, called low $(L)$ and high $(H)$. I assume that society wants to redistribute from high to low ability individuals.

Because single-crossingness conditions drive optimal tax results, I first analyze which conditions are reasonable and, related, which combinations of conditions are compatible (subsection 4.1). Afterwards, I study optimal

\footnotetext{
${ }^{17}$ We have $M C H(c, h, w, \theta)=-\frac{U_{h}^{\prime}}{U_{c}^{\prime}(c, h, w, \theta, w)}>0$ and $M C W(c, h, w, \theta)=-\frac{U_{w}^{\prime}(c, h, w, \theta)}{U_{c}^{\prime}(c, h, w, \theta)}>0$.
} 
taxation if only earnings are observable (subsection 4.2) and if also hours and wages are observable for low earners (subsection 4.3).

\subsection{Single-crossingness conditions}

In section $3 \mathrm{I}$ introduced examples of single-crossingness conditions and showed how these conditions define how ability affects choices. As singlecrossingness conditions drive optimal tax results, it is important to answer several questions. Are some conditions more reasonable than others? And how are the different conditions linked to each other and are some combinations therefore not possible?

First, I start with the Spence-Mirrlees condition.

Assumption A. The utility function $V$ satisfies $M C Y_{\theta}^{\prime}<0$. As a consequence, if taxes are function of earnings only, then higher ability individuals always choose higher gross earnings.

I impose this assumption to stick as close as possible to the standard optimal tax literature. It implies that redistribution from high to low ability individuals is equivalent to redistribution from the rich to the poor.

Second, concerning the sign of $M W H_{\theta}^{\prime}$, proposition 3 tells us that it cannot be chosen arbitrarily.

Proposition 3. There do not exist utility functions $U$ such that $M W H_{\theta}^{\prime} \geq 0$ hold. As a consequence, there do not exist utility functions such that higher ability individuals always choose more hours (combined with lower wages) to reach a given level of gross earnings.

Assumption B follows naturally.

Assumption B. The utility function $U$ satisfies $M W H_{\theta}^{\prime}<0$. As a consequence, higher ability individuals always choose less hours (and thus a higher wage rate) to reach a given level of gross earnings.

Third, I must define the signs of $M C W_{\theta}^{\prime}$ and $M C H_{\theta}^{\prime}$. Although a priori four combinations are possible, proposition 4 tells us that only two combinations are compatible (given assumptions $\mathrm{A}$ and $\mathrm{B}$ ). 
Proposition 4. The combination $M C H_{\theta}^{\prime}>0$ and $M C W_{\theta}^{\prime}>0$ contradicts the Spence-Mirrlees condition (assumption A). The combination $\mathrm{MCH}_{\theta}^{\prime}<0$ and $M C W_{\theta}^{\prime}>0$ contradicts proposition 3 (and thus assumption B).

Assumption $\mathrm{C}$ follows, again, naturally: ${ }^{18}$

Assumption C. The utility function $U$ satisfies $M C W_{\theta}^{\prime}<0$. As a consequence, if taxes are a function of hours and wages, then higher ability individuals would always choose higher wages for a given number of labour hours. In addition, the utility function $U$ satisfies either $M C H_{\theta}^{\prime}<0(\mathrm{C} 1)$ or $M C H_{\theta}^{\prime}>0(\mathrm{C} 2)$. As a consequence, if taxes are a function of hours and wages, then higher ability individuals would always choose to work either more hours $(\mathrm{C} 1)$ or less hours $(\mathrm{C} 2)$ for a given wage rate.

In the next subsections, I analyze optimal taxation under assumption A (subsection 4.2) and under assumptions B and C (subsection 4.3). Two final questions remain however.

First, do there exist preferences (represented by the utility function $u$ ) and production technologies (summarized by the production function $f$ ) such that assumptions A, B, and C are satisfied? If not, then all later results would be meaningless. Fortunately, proposition 5 shows that CEStype utility and production functions work well.

Proposition 5. Let $\mathbf{e}=\left(e_{1}, e_{2}, \ldots, e_{J}\right)$ be the $J$-dimensional vector of effort. Consider a utility function

$$
u:(c, h, \mathbf{e}) \mapsto \frac{1}{1-\alpha} c^{1-\alpha}-\frac{1}{1+\gamma}\left[\eta h^{1+\beta}+(1-\eta)\left(\sum_{j=1}^{J} \kappa_{j}\left(e_{j}\right)^{1+\delta}\right)^{\frac{1+\beta}{1+\delta}}\right]^{\frac{1+\gamma}{1+\beta}}
$$

with $\alpha, \beta, \gamma, \delta>0,0<\eta<1$, and all $\kappa_{j}>0$ with $\sum_{j=1}^{J} \kappa_{j}=19$ Consider a production function

$$
f: \mathbf{e} \mapsto\left(\sum_{j=1}^{J} \nu_{j}\left(e_{j}\right)^{\frac{\sigma-1}{\sigma}}\right)^{\frac{\sigma}{\sigma-1}},
$$

\footnotetext{
${ }^{18}$ Although $M C H_{\theta}^{\prime}=0$ is possible, I stick to strict conditions everywhere.

${ }^{19}$ If $\alpha=1$, then the utility-of-consumption function is defined as $\ln c$.
} 
with $\sigma>0$ and all $\nu_{j}>0$ with $\sum_{j=1}^{J} \nu_{j}=1$. For these specifications, assumptions A, B, and either $\mathrm{C} 1$ (if $\gamma>\beta$ ) or $\mathrm{C} 2$ (if $\gamma<\beta$ ) hold.

Second, which of the two assumptions, $\mathrm{C} 1$ or $\mathrm{C} 2$, is more likely? This is an empirical question that is hard to answer a priori. Suppose, for now, that effort is unidimensional and the utility function $u$ is additively separable between consumption and labour. If the disutility of working more hours is higher at higher levels of effort, then assumption C1 holds. This seems likely if effort measures, e.g., how physically challenging a job is (and ability then measures physical ability): working an extra hour implies more disutility if the job is (physically) harder. If the disutility of working more hours is lower at higher levels of effort, then assumption C2 holds. This is not implausible if, e.g., effort measures how intellectually challenging a job is (and ability then measures intellectual ability): working an extra hour leads to more disutility if the job is (intellectually) less challenging (i.e., more boring). More realistically, if effort is multidimensional, including physical and intellectual effort, then their relative importance will decide whether $\mathrm{C} 1$ or C2 (or none of the two) holds.

\subsection{Optimal taxation if only earnings can be taxed}

If only earnings can be taxed, then Pareto efficient redistribution from high to low ability individuals follows from

$$
\begin{gathered}
\max _{c_{L}, y_{L}, c_{H}, y_{H}} V\left(c_{L}, y_{L}, \theta_{L}\right) \quad \text { subject to } \\
V\left(c_{H}, y_{H}, \theta_{H}\right) \geq \underline{v}, \\
V\left(c_{H}, y_{H}, \theta_{H}\right) \geq V\left(c_{L}, y_{L}, \theta_{H}\right), \\
n_{L}\left(y_{L}-c_{L}\right)+n_{H}\left(y_{H}-c_{H}\right) \geq R_{0},
\end{gathered}
$$

with $n_{i}$ the number of individuals with ability type $i=L, H$. Constraint 11 guarantees a minimal utility level $\underline{v}$ to high type individuals. Constraint 12. is the self-selection constraint of the high type 20 It restrict the set

\footnotetext{
${ }^{20}$ Because pooling cannot be Pareto efficient and because I focus on redistribution from high to low ability individuals, only the self-selection constraint of the high type will be binding at the (second-best) optimum.
} 
of allocations to those that can be implemented by a tax scheme based on gross earnings only. Constraint $(13)$ is the budget constraint requiring that taxation raises an exogenous amount of revenues $R_{0}$.

The above formulation of the problem hides the fact that there is an optimal choice of jobs, conditional on earnings, underlying the function $V$ (defined in proposition 2). Nevertheless, the optimal tax problem is, in the end, identical to the one in Stiglitz (1982). Proposition 6 follows immediately.

Proposition 6. Suppose assumption A holds. If society wants to redistribute from high to low ability individuals in a Pareto efficient way, then there should be no distortion of high earners at the optimum. For low earners, the marginal earnings tax rate should be positive at the optimum.

Proposition 6 tells us that the number of intensive margins does not matter for signing the marginal earnings tax rate faced by low earners. So, how individuals change their earnings - through hours, wages, or a mixture of both-does not matter. Only the change in earnings matters in the end and is therefore a sufficient statistic for optimal earnings tax policy ${ }^{21}$

\subsection{Optimal taxation if hours and wages can be taxed}

If the hours and wages of (only) low earners are observable for tax purposes, then Pareto efficient redistribution from high to low ability individuals follows from

$$
\begin{gathered}
\max _{c_{L}, h_{L}, w_{L}, c_{H}, y_{H}} U\left(c_{L}, h_{L}, w_{L}, \theta_{L}\right) \text { subject to } \\
V\left(c_{H}, y_{H}, \theta_{H}\right) \geq \underline{v} \\
V\left(c_{H}, y_{H}, \theta_{H}\right) \geq U\left(c_{L}, h_{L}, w_{L}, \theta_{H}\right), \\
n_{L}\left(w_{L} h_{L}-c_{L}\right)+n_{H}\left(y_{H}-c_{H}\right) \geq R_{0} .
\end{gathered}
$$

The self-selection constraint of the high type (15) now restricts the set of allocations to those that can be implemented by a tax scheme that is based on earnings only for high earners, but on both hours and wages for low earners 22

\footnotetext{
${ }^{21}$ See Chetty (2009) for an overview of the sufficient statistics literature.

${ }^{22}$ Although not in line with the evidence reviewed in the introduction, all results would remain the same if also the hours and wages of high earners were observable.
} 
Pareto efficient redistribution from high to low ability individuals implies, as usual, that the high type remains undistorted at the margin. The more interesting question is what happens for low earners.

Recall Table1. The fiscal treatment of these three conditional margins for low earners depends on the preferences of mimickers - high ability individuals pretending having a low ability type - relative to low ability individuals. As a general rule, the fiscal treatment of each margin must be such that the direction that mimickers like (dislike) is discouraged (encouraged), and thus taxed (subsidized). Such a fiscal treatment will relax the self-selection constraint (15) and allows to further increase the utility of low ability individuals without hurting high ability individuals (who remain at utility level v) and without changing the tax revenues (which remain at level $R_{0}$ ).

Proposition 7 summarizes the main result. In a nutshell: working more hours for the same earnings should be subsidized, earning more by higher wages should be taxed, and earning more by working more hours should either be taxed or subsidized.

Proposition 7. Suppose assumptions B and C hold. If society wants to redistribute from high to low ability individuals in a Pareto efficient way, then there should be no distortion for high earners at the optimum. For low earners,

(7.1) the earnings-conditional marginal tax rate on hours should be negative, i.e., $T_{h}^{\prime}\left(h_{L}, w_{L}\right)-T_{w}^{\prime}\left(h_{L}, w_{L}\right) w_{L} / h_{L}<0$, at the optimum,

(7.2) the hours-conditional marginal tax rate on wages should be positive, i.e., $T_{w}^{\prime}\left(h_{L}, w_{L}\right)>0$, at the optimum, and

(7.3) the wage-conditional marginal tax rate on hours should be positive, i.e., $T_{h}^{\prime}\left(h_{L}, w_{L}\right)>0$, at the optimum if assumption $\mathrm{C} 1$ holds and negative, i.e., $T_{h}^{\prime}\left(h_{L}, w_{L}\right)<0$, at the optimum if assumption $\mathrm{C} 2$ holds.

In words, Proposition 7 tells us that, at the low earners' margin,

(7.1) individuals who have the same earnings, but work more hours at a lower wage rate should pay less taxes, 
(7.2) individuals who work the same hours at a higher wage rate should pay more taxes, and

(7.3) individuals who work more hours at the same wage rate should either pay more taxes $(\mathrm{C} 1)$ or less taxes $(\mathrm{C} 2)$.

The stylized version of the 'Werkbonus' in Belgium, introduced and discussed in subsection 2.2, is consistent with proposition 7 (assuming C1).

I finish this section with a visualization of proposition 7 . The iso-tax curve, denoted $w_{I T}: h \mapsto w_{I T}(h)$, collects all jobs that pay the same taxes as the low earner at the optimum and is thus implicitly defined as $T\left(h, w_{I T}(h)\right)=T\left(h_{L}, w_{L}\right)$. The iso-earnings curve $w_{I E}: h \mapsto w_{I E}(h)$ collects all jobs that pay the same gross earnings as the low earner at the optimum and is defined as $w_{I E}(h)=w_{L} h_{L} / h$. The slope of the iso-tax curve for low earners at the optimum is $w_{I T}^{\prime}\left(h_{L}\right)=-T_{h}^{\prime}\left(h_{L}, w_{L}\right) / T_{w}^{\prime}\left(h_{L}, w_{L}\right)$ and the slope of the iso-earnings curve for low earners at the optimum is $w_{I E}^{\prime}\left(h_{L}\right)=-w_{L} / h_{L}<0$. Proposition 8 follows directly from proposition 7 (without proof).

Proposition 8. According to proposition 7.1, the slope of the iso-tax-curve for low earners $w_{I T}^{\prime}\left(h_{L}\right)$ will be larger than the slope of the iso-earnings curve $w_{I E}^{\prime}\left(h_{L}\right)$, at the optimum. In addition, according to propositions 7.2 and 7.3 , the slope $w_{I T}^{\prime}\left(h_{L}\right)$ can be either negative (if C1 holds) or positive (if $\mathrm{C} 2$ holds), at the optimum.

Figure 1 visualizes the main result. It depicts the iso-earnings curve (the thin line) and the iso-tax curve (the solid line) for the low earner at the optimum if assumption C1 (left-hand panel) or C2 (right-hand panel) holds. The vertical arrows correspond with choosing a different wage rate for the same hours worked, the horizontal arrows correspond with choosing different hours worked for the same wage rate, and the arrows along the iso-earnings curve indicate working different hours at different wage rates for the same gross earnings. The signs indicate whether more taxes $(+)$ or less taxes $(-)$ must be paid in the direction of the arrow. Be aware that Figure 1 shows a local result, which holds only in a neighbourhood of $\left(w_{L}, h_{L}\right)$; moreover, Figure 1 assumes a differentiable tax scheme. 
Figure 1: Conditional earnings subsidies for low earners

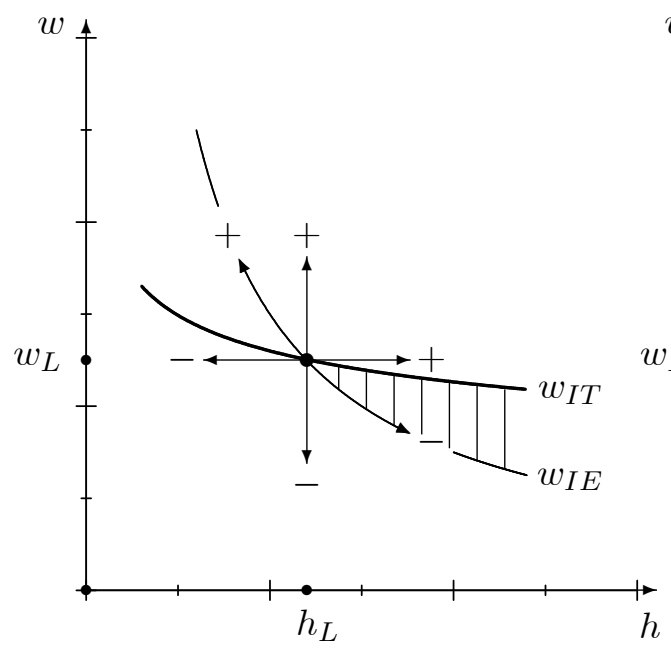

C1 holds

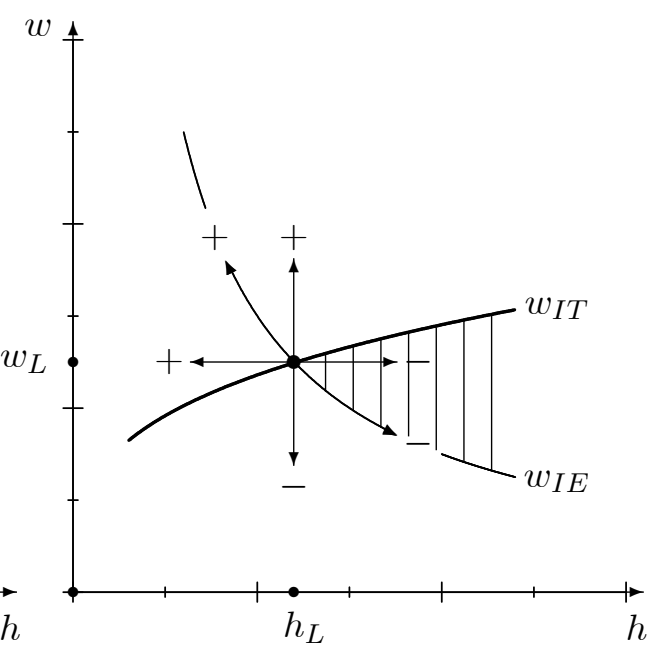

C2 holds

Because the iso-earnings curve and the iso-tax curve do not coincide, conditional earnings subsidies for low earners occur in each panel. Indeed, the earnings of low earners should be subsidized, but only in the direction of the hatched area, i.e., if their earnings increase by working more hours at a sufficiently low wage rate (lower than $w_{L}$ if $\mathrm{C} 1$ holds and similar to $w_{L}$ if C2 holds).

\section{Conclusion}

This paper starts from the observation that having low earnings is often not sufficient to be eligible for in-work tax credits. Indeed, several countries also impose that either hours worked are sufficiently high or that the wage rate is sufficiently low. The Working Tax Credit in the United Kingdom and the 'Werkbonus' in Belgium provide two typical examples.

To derive a theoretical justification for such additional conditions, I analyze Pareto efficient redistribution from high to low ability individuals in a model where labour has several intensive margins. Besides labour hours, also labour effort - a vector of unpleasant, but productive features of labour - is 
an object of choice. Effort and ability-both unobserved by the plannerdetermine the wage rate.

Conditional earnings subsidies for low earners turn out to be optimal, i.e., the earnings of low earners should be subsidized, but only if they earn more by working more hours at a sufficiently low wage rate. These additional conditions enhance redistribution by deterring high ability individuals to mimick low ability individuals.

The optimal tax results in this paper are qualitative in nature. A more detailed quantitative analysis, which should ideally include the possibility of misreporting hours and wages, is left for future research. 


\section{References}

Allingham, M.G., 1975, Towards an ability tax, Journal of Public Economics $4,361-376$.

Beaudry, P., Blackorby, C., Szalay, D., 2009, Taxes and employment subsidies in optimal redistribution programs, American Economic Review 99(1), 216-242.

Blomquist, S., 1981, Comparison of tax bases for a personal tax, Scandinavian Journal of Economics 83(3), 390-407.

Blomquist, S., 1984, The wage rate tax: An alternative to the income tax? Scandinavian Journal of Economics 86(2), 269-285.

Blomquist, S., Selin, H., 2010, Hourly wage rate and taxable labor income responsiveness to changes in marginal tax rates, Journal of Public Economics 94, 878-889.

Blundell, R., Shephard, A., 2012, Employment, hours of work and the optimal taxation of low-income families, Review of Economic Studies 79, 481510 .

Boadway, R., 2012, From Optimal Tax Theory to Tax Policy: Retrospective and Prospective Views, Munich Lectures in Economics, MIT Press.

Boadway, R., Marchand, M., Pestieau, P., Racionero, M, 2002, Optimal redistribution with heterogeneous preferences for leisure, Journal of Public Economic Theory 4(4), 475-498.

Cahuc, P., Carcillo, S., 2014, The detaxation of overtime hours: lessons from the French experiment, Journal of Labor Economics 32(2), 361-400.

Chetty, R., 2009, Sufficient statistics for welfare analysis: a bridge between structural and reduced-form methods, Annual Review of Economics 1, 451488 .

Choné, P., Laroque, G., 2010, Negative marginal tax rates and heterogeneity, American Economic Review 100, 2532-2547.

Choné, P., Laroque, G., 2011, Optimal taxation in the extensive model, Journal of Economic Theory 146, 425-453. 
Diamond, P., 1980, Income taxation with fixed hours of work, Journal of Public Economics 13, 10l-110.

Farhi, E., Gabaix, X., 2017, Optimal taxation with behavioral agents, mimeo. Fleurbaey, M., Maniquet, F., 2006, Fair income tax, Review of Economic Studies 73, 55-83.

Gentry, W., Hubbard, R., 2004, The effects of progressive income taxation on job turnover, Journal of Public Economics 88(11), 2301-2322.

Gerritsen, A., 2016, Optimal taxation when people do not maximize wellbeing, Journal of Public Economics 144, 122-139.

Helpman, E., Sadka, E., 1978, Optimal taxation of full income, International Economic Review 19(1), 247-251.

Kanbur, R., Keen, M., Tuomala, M., 1994, Optimal non-linear income taxation for the alleviation of income-poverty, European Economic Review 98, $701-719$.

Kanbur, R., Pirttilä, J., Tuomala, M., 2006, Non-welfarist optimal taxation and behavioural public economics, Journal of Economic Surveys 20, 849868.

Kesselman, J.R., 1976, Egalitarianism of earnings and income taxes, Journal of Public Economics 5, 285-301.

Mirrlees, J., 1971, An exploration in the theory of optimum income taxation, Review of Economic Studies 38(114), 175-208.

Nishimura, Y., 2004, Tax implementability of fair allocations, Review of Economic Design 9, 31-41.

OECD, 2011, Taxation and Employment, OECD tax policy studies 21, OECD Publishing.

Pirttilä, J., Tuomala, M., 2004, Poverty alleviation and tax policy, European Economic Review 48, 1075-1090.

Powell, D., 2010, Heterogeneity in income tax incidence: are the wages of dangerous jobs more responsive to tax changes than the wages of save jobs? RAND working paper WR-706-1. 
Powell, D., Shan, H., 2012, Income taxes, compensating differentials, and occupational choice: How taxes distort the wage-amenity decision, American Economic Journal: Economic Policy 4(1), 224-247.

Saez, E., 2002, Optimal income transfer programs: intensive versus extensive labor supply responses, Quarterly Journal of Economics 117(3), 1039-1073.

Stiglitz, J.E., 1982, Self-selection and Pareto efficient taxation, Journal of Public Economics 17, 213-240.

Tillmann, G., 2005, The equity-efficiency trade-off reconsidered, Social Choice and Welfare 24, 63-81.

Wagstaff, P., 1975, A Benthamite wages policy, Review of Economic Studies $42(4), 571-580$.

Werning, I., 2007, Pareto efficient income taxation, mimeo.

\section{Webpages}

WTC webpage, 15/06/18, https://www.gov.uk/working-tax-credit.

IWTC webpage, 15/06/18, http://www.ird.govt.nz/wff-tax-credits/ understanding/all-about/iwtc/in-work-tax-credit.html.

WFP webpage, 15/06/18, http://www.citizensinformation.ie/en/social_ welfare/social_welfare_payments/social_welfare_payments_to_families and_children/family_income_supplement.html.

WB webpage, 15/06/18, https://www.socialsecurity.be/employer/ instructions/dmfa/nl/latest/instructions/deductions/workers_reductions/ workbonus.html.

PPE wikipage, 15/06/18, https://en.wikipedia.org/wiki/Prime_pour_l'emploi. 


\section{Proof of proposition 1}

Proposition 1 is an application of the envelope theorem. First, because $U(c, h, w, \theta)=u(c, h, \mathbf{e}(c, h, w, \theta))$, I get

$$
\begin{aligned}
U_{c}^{\prime}(c, h, w, \theta)= & u_{c}^{\prime}(c, h, \mathbf{e}(c, h, w, \theta))+ \\
& \sum_{j=1}^{J} u_{j}^{\prime}(c, h, \mathbf{e}(c, h, w, \theta)) e_{j, c}^{\prime}(c, h, w, \theta), \\
U_{h}^{\prime}(c, h, w, \theta)= & u_{h}^{\prime}(c, h, \mathbf{e}(c, h, w, \theta))+ \\
& \sum_{j=1}^{J} u_{j}^{\prime}(c, h, \mathbf{e}(c, h, w, \theta)) e_{j, h}^{\prime}(c, h, w, \theta), \\
U_{w}^{\prime}(c, h, w, \theta)= & \sum_{j=1}^{J} u_{j}^{\prime}(c, h, \mathbf{e}(c, h, w, \theta)) e_{j, w}^{\prime}(c, h, w, \theta), \\
U_{\theta}^{\prime}(c, h, w, \theta)= & \sum_{j=1}^{J} u_{j}^{\prime}(c, h, \mathbf{e}(c, h, w, \theta)) e_{j, \theta}^{\prime}(c, h, w, \theta),
\end{aligned}
$$

where I use $j=1,2, \ldots, J$ to refer to the different dimensions of effort.

Second, using the first-order conditions of the problem

$$
\max _{\mathbf{e} \geq 0} u(c, h, \mathbf{e}) \text { such that } \theta f(\mathbf{e}) \geq w,
$$

with Lagrange multiplier $\lambda>0$, one obtains

$$
u_{j}^{\prime}(c, h, \mathbf{e}(c, h, w, \theta))+\lambda \theta f_{j}^{\prime}(\mathbf{e}(c, h, w, \theta))=0,
$$

for $j=1,2, \ldots, J$, and

$$
\theta f(\mathbf{e}(c, h, w, \theta))=w .
$$

Taking derivatives of this last equation (w.r.t. $c, h, w$, and $\theta$ ), I get

$$
\begin{aligned}
\theta \sum_{j=1}^{J} f_{j}^{\prime}(\mathbf{e}(c, h, w, \theta)) \times e_{j, c}^{\prime}(c, h, w, \theta) & =0 \\
\theta \sum_{j=1}^{J} f_{j}^{\prime}(\mathbf{e}(c, h, w, \theta)) \times e_{j, h}^{\prime}(c, h, w, \theta) & =0 \\
\theta \sum_{j=1}^{J} f_{j}^{\prime}(\mathbf{e}(c, h, w, \theta)) \times e_{j, w}^{\prime}(c, h, w, \theta) & =1, \\
\theta \sum_{j=1}^{J} f_{j}^{\prime}(\mathbf{e}(c, h, w, \theta)) \times e_{j, \theta}^{\prime}(c, h, w, \theta) & =-f(\mathbf{e}(c, h, w, \theta)) .
\end{aligned}
$$


Third, using equations (23)-(27) in (17)-(22), I get

$$
\begin{aligned}
U_{c}^{\prime}(c, h, w, \theta) & =u_{c}^{\prime}(c, h, \mathbf{e}(c, h, w, \theta))>0, \\
U_{h}^{\prime}(c, h, w, \theta) & =u_{h}^{\prime}(c, h, \mathbf{e}(c, h, w, \theta))<0, \\
U_{w}^{\prime}(c, h, w, \theta) & =-\lambda<0, \\
U_{\theta}^{\prime}(c, h, w, \theta) & =\lambda f(\mathbf{e}(c, h, w, \theta))>0,
\end{aligned}
$$

as required.

\section{Proof of proposition 2}

Proposition 2 is an application of the envelope theorem. First, because $V(c, y, \theta)=U(c, \hat{H}(c, y, \theta), \hat{W}(c, y, \theta), \theta)$, the partial derivatives are

$$
\begin{aligned}
V_{c}^{\prime}(c, y, \theta)=\quad & U_{c}^{\prime}(c, \hat{H}(c, y, \theta), \hat{W}(c, y, \theta), \theta)+ \\
& U_{h}^{\prime}(c, \hat{H}(c, y, \theta), \hat{W}(c, y, \theta), \theta) \hat{H}_{c}^{\prime}(c, y, \theta)+ \\
& U_{w}^{\prime}(c, \hat{H}(c, y, \theta), \hat{W}(c, y, \theta), \theta) \hat{W}_{c}^{\prime}(c, y, \theta), \\
V_{y}^{\prime}(c, y, \theta)=\quad & U_{h}^{\prime}(c, \hat{H}(c, y, \theta), \hat{W}(c, y, \theta), \theta) \hat{H}_{y}^{\prime}(c, y, \theta)+ \\
& U_{w}^{\prime}(c, \hat{H}(c, y, \theta), \hat{W}(c, y, \theta), \theta) \hat{W}_{y}^{\prime}(c, y, \theta), \\
V_{\theta}^{\prime}(c, y, \theta)=\quad & U_{\theta}^{\prime}(c, \hat{H}(c, y, \theta), \hat{W}(c, y, \theta), \theta)+ \\
& U_{h}^{\prime}(c, \hat{H}(c, y, \theta), \hat{W}(c, y, \theta), \theta) \hat{H}_{\theta}^{\prime}(c, y, \theta)+ \\
& U_{w}^{\prime}(c, \hat{H}(c, y, \theta), \hat{W}(c, y, \theta), \theta) \hat{W}_{\theta}^{\prime}(c, y, \theta) .
\end{aligned}
$$

Second, $\hat{H}(c, y, \theta)$ and $\hat{W}(c, y, \theta)$ must satisfy the first-order condition (4), i.e.,

$$
\frac{U_{h}^{\prime}(c, \hat{H}(c, y, \theta), \hat{W}(c, y, \theta), \theta)}{U_{w}^{\prime}(c, \hat{H}(c, y, \theta), \hat{W}(c, y, \theta), \theta)}=\frac{\hat{W}(c, y, \theta)}{\hat{H}(c, y, \theta)} .
$$

In addition, also $\hat{W}(c, y, \theta) \hat{H}(c, y, \theta)=y$ must hold; taking derivatives on both sides with respect to $c, y$, or $\theta$ implies

$$
\begin{aligned}
& \hat{W}_{c}^{\prime}(c, y, \theta) \hat{H}(c, y, \theta)+\hat{W}(c, y, \theta) \hat{H}_{c}^{\prime}(c, y, \theta)=0, \\
& \hat{W}_{y}^{\prime}(c, y, \theta) \hat{H}(c, y, \theta)+\hat{W}(c, y, \theta) \hat{H}_{y}^{\prime}(c, y, \theta)=1, \\
& \hat{W}_{\theta}^{\prime}(c, y, \theta) \hat{H}(c, y, \theta)+\hat{W}(c, y, \theta) \hat{H}_{\theta}^{\prime}(c, y, \theta)=0 .
\end{aligned}
$$


Combining these elements, I get

$$
\begin{aligned}
V_{c}^{\prime}(c, y, \theta) & =U_{c}^{\prime}(c, \hat{H}(c, y, \theta), \hat{W}(c, y, \theta), \theta)>0, \\
V_{y}^{\prime}(c, y, \theta) & =\frac{U_{w}^{\prime}(c, h, \hat{W}(c, y, \theta), \theta)}{\hat{H}(c, y, \theta)}<0, \\
V_{\theta}^{\prime}(c, y, \theta) & =U_{\theta}^{\prime}(c, \hat{H}(c, y, \theta), \hat{W}(c, y, \theta), \theta)>0,
\end{aligned}
$$

where the signs follow from proposition 1.

\section{Proof of proposition 3}

Suppose there exists a utility function $U$ for which $M W H_{\theta}^{\prime} \geq 0$ holds. If true, then there exists a utility function $U$ that implies $\hat{H}_{\theta}^{\prime} \geq 0$-with, recall, $\hat{H}(c, y, \theta)$ the solution to problem 3 .

First, $U(c, h, w, \theta)$ is defined as $u(c, h, \mathbf{e}(c, h, w, \theta))$, where $\mathbf{e}(c, h, w, \theta)$ solves the problem

$$
\max _{\mathbf{e} \geq \mathbf{0}} u(c, h, \mathbf{e}) \text { such that } \theta f(\mathbf{e}) \geq w .
$$

Rewriting the constraint as $f(\mathbf{e}) \geq w / \theta$, it follows immediately that $\mathbf{e}$ only depends on the ratio $w / \theta$. I write $\tilde{\mathbf{e}}(c, h, w / \theta)$ and $\tilde{U}(c, h, w / \theta)=$ $u(c, h, \tilde{\mathbf{e}}(c, h, w / \theta))$.

Second, $\hat{H}(c, y, \theta)$ and $\hat{W}(c, y, \theta)$ follow from the problem

$$
\max _{h, w \geq 0} U(c, h, w, \theta) \text { such that } w h \geq y,
$$

which can be equivalently written as

$$
\max _{h, w \geq 0} \tilde{U}\left(c, h, \frac{w}{\theta}\right) \text { such that } \frac{w}{\theta} h \geq \frac{y}{\theta} .
$$

Changing variable from $w / \theta$ to $k$, the solutions of the problem

$$
\max _{h, k \geq 0} \tilde{U}(c, h, k) \text { such that } k h \geq \frac{y}{\theta},
$$

depend only on the ratio $y / \theta$, say, $h(c, y / \theta)$ and $k(c, y / \theta)$. Moreover, one has

$$
\hat{H}(c, y, \theta)=h(c, y / \theta) \text { and } \hat{W}(c, y, \theta)=\theta k(c, y / \theta) .
$$

Third, to show that $\hat{H}_{\theta}^{\prime} \geq 0$ is not possible I show that $h_{z}^{\prime}(c, z)>0$ must hold over some interval of $z$-values. Following proposition 1 , the function 
$\tilde{U}$ is strictly decreasing in $h$ and $k=w / \theta$, which implies $h(c, 0)=k(c, 0)=$ 0 . In addition, $k\left(c, \frac{y}{\theta}\right) h\left(c, \frac{y}{\theta}\right)=\frac{y}{\theta}$ must hold at the optimum, leading to $k\left(c, \frac{y}{\theta}\right)>0$ and $h\left(c, \frac{y}{\theta}\right)>0$ whenever $\frac{y}{\theta}>0$. Both conditions require that $h_{z}^{\prime}(c, z)>0$ must hold somewhere, as required.

\section{Proof of proposition 4}

First, I show that $M C Y_{\theta}^{\prime}<0, M C W_{\theta}^{\prime}>0$, and $M C H_{\theta}^{\prime}>0$ are not compatible. Using the definition of $M C Y$, equations (28) and (29), and the definition of $M C W$, one gets

$$
\begin{aligned}
M C Y(c, y, \theta) & =-\frac{U_{w}^{\prime}(c, h, \hat{W}(c, y, \theta), \theta)}{U_{c}^{\prime}(c, \hat{H}(c, y, \theta), \hat{W}(c, y, \theta), \theta) \hat{H}(c, y, \theta)}, \\
& =\frac{M C W(c, \hat{H}(c, y, \theta), \hat{W}(c, y, \theta), \theta)}{\hat{H}(c, y, \theta)} .
\end{aligned}
$$

Differentiating both sides with respect to $\theta$, the sign of $M C Y_{\theta}^{\prime}(c, y, \theta)$ must coincide with the sign of

$$
\begin{aligned}
& M C W_{\theta}^{\prime}(c, \hat{H}(c, y, \theta), \hat{W}(c, y, \theta), \theta) \hat{H}(c, y, \theta)- \\
& M C W(c, \hat{H}(c, y, \theta), \hat{W}(c, y, \theta), \theta) \hat{H}_{\theta}^{\prime}(c, y, \theta) .
\end{aligned}
$$

If $M C W_{\theta}^{\prime}>0$ and $M C H_{\theta}^{\prime}>0$ hold, then this expression becomes positive, because (i) $\hat{H}(c, y, \theta) \geq 0$ and $M C W(c, \hat{H}(c, y, \theta), \hat{W}(c, y, \theta), \theta)>0$ hold by definition and (ii) $\hat{H}_{\theta}^{\prime}(c, y, \theta)<0$ follows from $M C H_{\theta}^{\prime}>0$. But this is not compatible with $M C Y_{\theta}^{\prime}<0$, as required.

Second, I show that $M C H_{\theta}^{\prime}<0$ and $M C W_{\theta}^{\prime}>0$ are not possible. To see this, note that, by definition, $M W H$ is equal to $-M C H / M C W$. This implies that $M W H_{\theta}^{\prime}$ has the opposite sign of $M C H_{\theta}^{\prime} \times M C W-M C W_{\theta}^{\prime} \times M C H$. Now, if $M C H_{\theta}^{\prime}<0$ and $M C W_{\theta}^{\prime}>0$ were true, and because $M C H>0$ and $M C W>0$ hold by definition, one gets $M W H_{\theta}^{\prime}>0$. This however contradicts proposition 3 , as required.

\section{Proof of proposition 5}

Assumptions B and $\mathrm{C}$ relate to the function $U$ (defined in proposition 1) and assumption A relates to the function $V$ (defined in proposition 2). 
First, to derive the function $U$, I first derive the optimal effort vector that solves

$$
\max _{\mathbf{e} \geq \mathbf{0}} u(c, h, \mathbf{e}) \text { such that } \theta f(\mathbf{e}) \geq w,
$$

using

$$
u:(c, h, \mathbf{e}) \mapsto \frac{1}{1-\alpha} c^{1-\alpha}-\frac{1}{1+\gamma}\left[\eta h^{1+\beta}+(1-\eta)\left(\sum_{j=1}^{J} \kappa_{j}\left(e_{j}\right)^{1+\delta}\right)^{\frac{1+\beta}{1+\delta}}\right]^{\frac{1+\gamma}{1+\beta}},
$$

with $\alpha, \beta, \gamma, \delta>0,0<\eta<1$, and all $\kappa_{j}>0$ with $\sum_{j=1}^{J} \kappa_{j}=1$ as the utility function and

$$
f: \mathbf{e} \mapsto\left(\sum_{j=1}^{J} \nu_{j}\left(e_{j}\right)^{\frac{\sigma-1}{\sigma}}\right)^{\frac{\sigma}{\sigma-1}},
$$

with $\sigma>0$ and all $\nu_{j}>0$ with $\sum_{j=1}^{J} \nu_{j}=1$ as the production function.

The first-order conditions imply

$$
\frac{\kappa_{j}}{\kappa_{1}}\left(\frac{e_{j}}{e_{1}}\right)^{\delta}=\frac{\nu_{j}}{\nu_{1}}\left(\frac{e_{j}}{e_{1}}\right)^{\frac{-1}{\sigma}}
$$

for each $j \neq 1$, or equivalently,

$$
e_{j}=\left(\frac{\nu_{j}}{\nu_{1}} \frac{\kappa_{1}}{\kappa_{j}}\right)^{\frac{\sigma}{1+\delta \sigma}} e_{1}
$$

for each $j$ (including $j=1$ ). Because $f(\mathbf{e})=w / \theta$ must hold at the optimum, I find

$$
e_{1}=\left(\sum_{j=1}^{J} \nu_{j}\left(\frac{\nu_{j}}{\nu_{1}} \frac{\kappa_{1}}{\kappa_{j}}\right)^{\frac{\sigma-1}{1+\delta \sigma}}\right)^{\frac{\sigma}{1-\sigma}} \frac{w}{\theta}
$$

and thus

$$
e_{j}=\left(\frac{\nu_{j}}{\nu_{1}} \frac{\kappa_{1}}{\kappa_{j}}\right)^{\frac{\sigma}{1+\delta \sigma}}\left(\sum_{j=1}^{J} \nu_{j}\left(\frac{\nu_{j}}{\nu_{1}} \frac{\kappa_{1}}{\kappa_{j}}\right)^{\frac{\sigma-1}{1+\delta \sigma}}\right)^{\frac{\sigma}{1-\sigma}} \frac{w}{\theta},
$$

for all $j$. To find the indirect utility function $U$, I plug in the solution $\mathbf{e}(c, h, w, \theta)$ in the direct utility function $u$. I get

$$
\begin{aligned}
U(c, h, w, \theta) & =u(c, h, \mathbf{e}(c, h, w, \theta)) \\
& =\frac{1}{1-\alpha} c^{1-\alpha}-\frac{1}{1+\gamma}\left(\eta h^{1+\beta}+(1-\eta) C(\boldsymbol{\nu}, \boldsymbol{\kappa})\left(\frac{w}{\theta}\right)^{1+\beta}\right)^{\frac{1+\gamma}{1+\beta}}
\end{aligned}
$$


with

$$
C(\boldsymbol{\nu}, \boldsymbol{\kappa})=\left(\sum_{j=1}^{J}\left(\kappa_{j}\right)^{\frac{1-\sigma}{1+\delta \sigma}}\left(\nu_{j}\right)^{\frac{\sigma(1+\delta)}{1+\delta \sigma}}\right)^{\frac{(1+\beta)(1+\delta \sigma)}{(1+\delta)(1-\sigma)}}>0 .
$$

I can now derive the different marginal rates of substitution; I get

$$
\begin{aligned}
M C H(c, h, w, \theta) & =-\frac{U_{h}^{\prime}(c, h, w, \theta)}{U_{c}^{\prime}(c, h, w, \theta)} \\
& =c^{\alpha}\left(\eta h^{1+\beta}+(1-\eta) C(\boldsymbol{\nu}, \boldsymbol{\kappa})\left(\frac{w}{\theta}\right)^{1+\beta}\right)^{\frac{\gamma-\beta}{1+\beta}} \eta h^{\beta},
\end{aligned}
$$

and

$$
\begin{aligned}
M C W(c, h, w, \theta) & =-\frac{U_{w}^{\prime}(c, h, w, \theta)}{U_{c}^{\prime}(c, h, w, \theta)} \\
& =\frac{\left(\eta h^{1+\beta}+(1-\eta) C(\boldsymbol{\nu}, \boldsymbol{\kappa})\left(\frac{w}{\theta}\right)^{1+\beta}\right)^{\frac{\gamma-\beta}{1+\beta}} w^{\beta} \theta^{-(1+\beta)}}{\left(c^{\alpha}(1-\eta) C(\boldsymbol{\nu}, \boldsymbol{\kappa})\right)^{-1}} .
\end{aligned}
$$

The signs of the derivatives of these marginal rates of substitution with respect to ability define the single-crossingness conditions. Because

$$
M C H_{\theta}^{\prime}(c, h, w, \theta)=-(\gamma-\beta) \frac{\left(\eta h^{1+\beta}+(1-\eta) C(\boldsymbol{\nu}, \boldsymbol{\kappa})\left(\frac{w}{\theta}\right)^{1+\beta}\right)^{\frac{\gamma-\beta}{1+\beta}-1}}{\theta\left(c^{\alpha} \eta h^{\beta}(1-\eta) C(\boldsymbol{\nu}, \boldsymbol{\kappa})\left(\frac{w}{\theta}\right)^{1+\beta}\right)^{-1}},
$$

the sign of $M C H_{\theta}^{\prime}$ depends on the sign of $\gamma-\beta$ and can thus be negative $(\gamma>\beta)$ or positive $(\gamma<\beta)$. Because

$$
M C W_{\theta}^{\prime}(c, h, w, \theta)=-\frac{\left[(1+\gamma)(1-\eta) C(\boldsymbol{\nu}, \boldsymbol{\kappa})\left(\frac{w}{\theta}\right)^{1+2 \beta}+(1+\beta)\left(\frac{w}{\theta}\right)^{\beta} \eta h^{1+\beta}\right]}{\theta^{2}\left(c^{\alpha}(1-\eta) C(\boldsymbol{\nu}, \boldsymbol{\kappa})\right)^{-1}\left(\eta h^{1+\beta}+(1-\eta) C(\boldsymbol{\nu}, \boldsymbol{\kappa})\left(\frac{w}{\theta}\right)^{1+\beta}\right)^{-\frac{\gamma-\beta}{1+\beta}}},
$$

the sign of $M C W_{\theta}^{\prime}$ is always (strictly) negative.

To derive the function $V$, I focus on problem (3). Using

$$
\begin{aligned}
M W H(c, h, w, \theta) & =-\frac{U_{h}^{\prime}(c, h, w, \theta)}{U_{w}^{\prime}(c, h, w, \theta)}=-\frac{M C H(c, h, w, \theta)}{M C W(c, h, w, \theta)}, \\
& =-\frac{\eta h^{\beta}}{(1-\eta) C(\boldsymbol{\nu}, \boldsymbol{\kappa}) w^{\beta} \theta^{-(1+\beta)}},
\end{aligned}
$$

the first-order condition (4) leads to

$$
h=\left(\frac{(1-\eta) C(\boldsymbol{\nu}, \boldsymbol{\kappa})}{\eta}\right)^{\frac{1}{1+\beta}} \frac{w}{\theta} .
$$


Because $w h=y$ must hold at the optimum, I get

$$
\begin{aligned}
\hat{H}(c, y, \theta) & =\sqrt{\left(\frac{(1-\eta) C(\boldsymbol{\nu}, \boldsymbol{\kappa})}{\eta}\right)^{\frac{1}{1+\beta}} \frac{y}{\theta}}, \\
\hat{W}(c, y, \theta) & =\theta \sqrt{\left(\frac{(1-\eta) C(\boldsymbol{\nu}, \boldsymbol{\kappa})}{\eta}\right)^{-\frac{1}{1+\beta}}} \frac{y}{\theta} .
\end{aligned}
$$

Plugged in in the utility function $U$, I find

$$
\begin{gathered}
V(c, y, \theta)=U(c, \hat{H}(c, y, \theta), \hat{W}(c, y, \theta), \theta)=\frac{1}{1-\alpha} c^{1-\alpha}- \\
\frac{1}{1+\gamma}\left(\eta\left(\frac{(1-\eta) C(\boldsymbol{\nu}, \boldsymbol{\kappa})}{\eta}\right)^{\frac{1}{2}}+(1-\eta) C(\boldsymbol{\nu}, \boldsymbol{\kappa})\left(\frac{(1-\eta) C(\boldsymbol{\nu}, \boldsymbol{\kappa})}{\eta}\right)^{-\frac{1}{2}}\right)^{\frac{1+\gamma}{1+\beta}}\left(\frac{y}{\theta}\right)^{\frac{1+\gamma}{2}} .
\end{gathered}
$$

The marginal rate of substitution is

$$
\begin{aligned}
M C Y(c, y, \theta) & =-\frac{U_{y}^{\prime}(c, h, w, \theta)}{U_{c}^{\prime}(c, h, w, \theta)} \\
& =\frac{\left(\eta\left(\frac{(1-\eta) C(\boldsymbol{\nu}, \boldsymbol{\kappa})}{\eta}\right)^{\frac{1}{2}}+(1-\eta) C(\boldsymbol{\nu}, \boldsymbol{\kappa})\left(\frac{(1-\eta) C(\boldsymbol{\nu}, \boldsymbol{\kappa})}{\eta}\right)^{-\frac{1}{2}}\right)^{\frac{1+\gamma}{1+\beta}}}{2 c^{-\alpha} y^{\frac{1-\gamma}{2}}} \theta^{-\frac{1+\gamma}{2}}
\end{aligned}
$$

which makes clear that the sign of $M C Y_{\theta}^{\prime}(c, y, \theta)$ depends on the sign of $-\frac{1+\gamma}{2}$, which is indeed negative.

\section{Proof of proposition 6}

The proof is essentially the same as in Stiglitz (1982). I add a proof for this paper to be self-contained. Consider the program

$$
\begin{gathered}
\max _{c_{L}, y_{L}, c_{H}, y_{H}} V\left(c_{L}, y_{L}, \theta_{L}\right) \quad \text { subject to } \\
V\left(c_{H}, y_{H}, \theta_{H}\right)-\underline{v} \geq 0, \\
V\left(c_{H}, y_{H}, \theta_{H}\right)-V\left(c_{L}, y_{L}, \theta_{H}\right) \geq 0, \\
n_{L}\left(y_{L}-c_{L}\right)+n_{H}\left(y_{H}-c_{H}\right)-R_{0} \geq 0,
\end{gathered}
$$

and let $\alpha, \beta$, and $\gamma$ be the Lagrange multipliers of the corresponding constraints. The first-order conditions (w.r.t. $\left.c_{L}, y_{L}, c_{H}, y_{H}\right)$ are 


$$
\begin{aligned}
V_{c}^{\prime}\left(c_{L}, y_{L}, \theta_{L}\right)-\beta V_{c}^{\prime}\left(c_{L}, y_{L}, \theta_{H}\right)-\gamma n_{L} & =0, \\
V_{y}^{\prime}\left(c_{L}, y_{L}, \theta_{L}\right)-\beta V_{y}^{\prime}\left(c_{L}, y_{L}, \theta_{H}\right)+\gamma n_{L} & =0, \\
(\alpha+\beta) V_{c}^{\prime}\left(c_{H}, y_{H}, \theta_{H}\right)-\gamma n_{H} & =0, \\
(\alpha+\beta) V_{y}^{\prime}\left(c_{H}, y_{H}, \theta_{H}\right)+\gamma n_{H} & =0 .
\end{aligned}
$$

Combining the first-order conditions (33) and (34), and using the definition of $M C Y$, one obtains

$$
\operatorname{MCY}\left(c_{H}, y_{H}, \theta_{H}\right)=1,
$$

and thus, using equation (8), I find $T^{\prime}\left(y_{H}\right)=0$ at the optimum.

Combining the first-order conditions (31) and (32), one obtains

$$
\frac{V_{y}^{\prime}\left(c_{L}, y_{L}, \theta_{L}\right)}{V_{c}^{\prime}\left(c_{L}, y_{L}, \theta_{L}\right)}=\frac{\beta V_{y}^{\prime}\left(c_{L}, y_{L}, \theta_{H}\right)-\gamma n_{L}}{\beta V_{c}^{\prime}\left(c_{L}, y_{L}, \theta_{H}\right)+\gamma n_{L}}
$$

which can also be written as

$$
\frac{V_{y}^{\prime}\left(c_{L}, y_{L}, \theta_{L}\right)}{V_{c}^{\prime}\left(c_{L}, y_{L}, \theta_{L}\right)}+\frac{\gamma n_{L}}{\beta V_{c}^{\prime}\left(c_{L}, y_{L}, \theta_{H}\right)}\left(\frac{V_{y}^{\prime}\left(c_{L}, y_{L}, \theta_{L}\right)}{V_{c}^{\prime}\left(c_{L}, y_{L}, \theta_{L}\right)}+1\right)=\frac{V_{y}^{\prime}\left(c_{L}, y_{L}, \theta_{H}\right)}{V_{c}^{\prime}\left(c_{L}, y_{L}, \theta_{H}\right)} .
$$

Using equation (8) and the definition of $M C Y$, I get ${ }^{23}$

$$
T^{\prime}\left(y_{L}\right)=-\frac{\beta V_{c}^{\prime}\left(c_{L}, y_{L}, \theta_{H}\right)}{\gamma n_{L}}\left[M C Y\left(c_{L}, y_{L}, \theta_{H}\right)-M C Y\left(c_{L}, y_{L}, \theta_{L}\right)\right] .
$$

Because the term between squared brackets is strictly negative by assumption $\mathrm{A}\left(M C Y_{\theta}^{\prime}<0\right)$, the marginal tax rate $T^{\prime}\left(y_{L}\right)$ must be strictly positive at the optimum.

\footnotetext{
${ }^{23}$ For the low earners, the marginal tax rate is not well-defined at the optimum. The reason is that the self-selection constraint imposes a kink in the tax scheme at $y_{L}$. I (always) use the left-derivative (here and later). This is without loss of generality for signing the marginal tax rates. To see this here, the left-derivative is defined as $T_{l}^{\prime}\left(y_{L}\right)=$ $1-M C Y\left(c_{L}, y_{L}, \theta_{L}\right)$ and the right-derivative as $T_{r}^{\prime}\left(y_{L}\right)=1-M C Y\left(c_{L}, y_{L}, \theta_{H}\right)$. Adding 1 to both sides of equation 35 and using equation (8), one can rewrite the obtained expression as

$$
\underbrace{\left(1+\frac{\gamma n_{L}}{\beta V_{c}^{\prime}\left(c_{L}, y_{L}, \theta_{H}\right)}\right)}_{>0} T_{l}^{\prime}\left(y_{L}\right)=T_{r}^{\prime}\left(y_{L}\right),
$$

which shows that the signs of both derivatives are the same, as required.
} 


\section{Proof of proposition 7}

Consider the program

$$
\begin{gathered}
\max _{c_{L}, h_{L}, w_{L}, c_{H}, y_{H}} U\left(c_{L}, h_{L}, w_{L}, \theta_{L}\right) \text { subject to } \\
V\left(c_{H}, y_{H}, \theta_{H}\right)-\underline{v} \geq 0, \\
V\left(c_{H}, y_{H}, \theta_{H}\right)-U\left(c_{L}, h_{L}, w_{L}, \theta_{H}\right) \geq 0, \\
n_{L}\left(w_{L} h_{L}-c_{L}\right)+n_{H}\left(y_{H}-c_{H}\right)-R_{0} \geq 0 .
\end{gathered}
$$

Let $\alpha, \beta$, and $\gamma$ be the Lagrange multipliers of the corresponding constraints.

The first-order conditions w.r.t. $c_{H}$ and $y_{H}$ are again equations (33) and (34) and lead therefore to the same result: no distortion at the top. The first-order conditions w.r.t. $c_{L}, h_{L}$, and $w_{L}$ are

$$
\begin{aligned}
U_{c}^{\prime}\left(c_{L}, h_{L}, w_{L}, \theta_{L}\right)-\beta U_{c}^{\prime}\left(c_{L}, h_{L}, w_{L}, \theta_{H}\right)-\gamma n_{L} & =0, \\
U_{h}^{\prime}\left(c_{L}, h_{L}, w_{L}, \theta_{L}\right)-\beta U_{h}^{\prime}\left(c_{L}, h_{L}, w_{L}, \theta_{H}\right)+\gamma n_{L} w_{L} & =0, \\
U_{w}^{\prime}\left(c_{L}, h_{L}, w_{L}, \theta_{L}\right)-\beta U_{w}^{\prime}\left(c_{L}, h_{L}, w_{L}, \theta_{H}\right)+\gamma n_{L} h_{L} & =0 .
\end{aligned}
$$

First, using equations (36) and (38), I get

$$
\frac{U_{w}^{\prime}\left(c_{L}, h_{L}, w_{L}, \theta_{L}\right)}{U_{c}^{\prime}\left(c_{L}, h_{L}, w_{L}, \theta_{L}\right)}=\frac{\beta U_{w}^{\prime}\left(c_{L}, h_{L}, w_{L}, \theta_{H}\right)-\gamma n_{L} h_{L}}{\beta U_{c}^{\prime}\left(c_{L}, h_{L}, w_{L}, \theta_{H}\right)+\gamma n_{L}} .
$$

This expression can be written as

$$
\frac{U_{w}^{\prime}\left(c_{L}, h_{L}, w_{L}, \theta_{L}\right)}{U_{c}^{\prime}\left(c_{L}, h_{L}, w_{L}, \theta_{L}\right)}=\frac{\frac{U_{w}^{\prime}\left(c_{L}, h_{L}, w_{L}, \theta_{H}\right)}{U_{c}^{\prime}\left(c_{L}, h_{L}, w_{L}, \theta_{H}\right)}-\frac{\gamma n_{L} h_{L}}{\beta U_{c}^{\prime}\left(c_{L}, h_{L}, w_{L}, \theta_{H}\right)}}{1+\frac{\gamma n_{L}}{\beta U_{c}^{\prime}\left(c_{L}, h_{L}, w_{L}, \theta_{H}\right)}},
$$

leading to

$$
\begin{aligned}
\frac{U_{w}^{\prime}\left(c_{L}, h_{L}, w_{L}, \theta_{L}\right)}{U_{c}^{\prime}\left(c_{L}, h_{L}, w_{L}, \theta_{L}\right)}+\left(\frac{U_{w}^{\prime}\left(c_{L}, h_{L}, w_{L}, \theta_{L}\right)}{U_{c}^{\prime}\left(c_{L}, h_{L}, w_{L}, \theta_{L}\right)}+h_{L}\right) \frac{\gamma n_{L}}{\beta U_{c}^{\prime}\left(c_{L}, h_{L}, w_{L}, \theta_{H}\right)} \\
=\frac{U_{w}^{\prime}\left(c_{L}, h_{L}, w_{L}, \theta_{H}\right)}{U_{c}^{\prime}\left(c_{L}, h_{L}, w_{L}, \theta_{H}\right)} .
\end{aligned}
$$

Using equation 10$)$ and the definition of $M C W$, I obtain

$$
\begin{aligned}
& T_{w}^{\prime}\left(h_{L}, w_{L}\right)=-\frac{\beta U_{c}^{\prime}\left(c_{L}, h_{L}, w_{L}, \theta_{H}\right)}{\gamma n_{L}} \times \\
& {\left[M C W\left(c_{L}, h_{L}, w_{L}, \theta_{H}\right)-M C W\left(c_{L}, h_{L}, w_{L}, \theta_{L}\right)\right] .}
\end{aligned}
$$


Because $M C W_{\theta}^{\prime}<0$ holds (assumption $\mathrm{C}$ ), the term between brackets is negative and thus $T_{w}^{\prime}\left(h_{L}, w_{L}\right)>0$ (hence, proposition 7.2).

Second, using equations (36) and (37), I get

$$
\frac{U_{h}^{\prime}\left(c_{L}, h_{L}, w_{L}, \theta_{L}\right)}{U_{c}^{\prime}\left(c_{L}, h_{L}, w_{L}, \theta_{L}\right)}=\frac{\beta U_{h}^{\prime}\left(c_{L}, h_{L}, w_{L}, \theta_{H}\right)-\gamma n_{L} w_{L}}{\beta U_{c}^{\prime}\left(c_{L}, h_{L}, w_{L}, \theta_{H}\right)+\gamma n_{L}} .
$$

Proceeding in the same way as before, one can rewrite this expression as

$$
\begin{aligned}
\frac{U_{h}^{\prime}\left(c_{L}, h_{L}, w_{L}, \theta_{L}\right)}{U_{c}^{\prime}\left(c_{L}, h_{L}, w_{L}, \theta_{L}\right)}+\left(\frac{U_{h}^{\prime}\left(c_{L}, h_{L}, w_{L}, \theta_{L}\right)}{U_{c}^{\prime}\left(c_{L}, h_{L}, w_{L}, \theta_{L}\right)}+w_{L}\right) \frac{\gamma n_{L}}{\beta U_{c}^{\prime}\left(c_{L}, h_{L}, w_{L}, \theta_{H}\right)} \\
=\frac{U_{h}^{\prime}\left(c_{L}, h_{L}, w_{L}, \theta_{H}\right)}{U_{c}^{\prime}\left(c_{L}, h_{L}, w_{L}, \theta_{H}\right)} .
\end{aligned}
$$

Now, using equation (9) and the definition of $M C H$, I obtain

$$
\begin{aligned}
& T_{h}^{\prime}\left(h_{L}, w_{L}\right)=-\frac{\beta U_{c}^{\prime}\left(c_{L}, h_{L}, w_{L}, \theta_{H}\right)}{\gamma n_{L}} \times \\
& \quad\left[M C H\left(c_{L}, h_{L}, w_{L}, \theta_{H}\right)-\operatorname{MCH}\left(c_{L}, h_{L}, w_{L}, \theta_{L}\right)\right] .
\end{aligned}
$$

The sign of $T_{h}^{\prime}\left(h_{L}, w_{L}\right)$ is thus inversely related to the sign of $M C H_{\theta}^{\prime}$ (hence, proposition 7.3).

Third, using equations (37) and (38) one obtains

$$
\frac{U_{h}^{\prime}\left(c_{L}, h_{L}, w_{L}, \theta_{L}\right)}{U_{w}^{\prime}\left(c_{L}, h_{L}, w_{L}, \theta_{L}\right)}=\frac{\beta U_{h}^{\prime}\left(c_{L}, h_{L}, w_{L}, \theta_{H}\right)-\gamma n_{L} w_{L}}{\beta U_{w}^{\prime}\left(c_{L}, h_{L}, w_{L}, \theta_{H}\right)-\gamma n_{L} h_{L}} .
$$

Proceeding in the same way as before, one gets after some manipulation

$$
\begin{array}{r}
\frac{U_{h}^{\prime}\left(c_{L}, h_{L}, w_{L}, \theta_{L}\right)}{U_{w}^{\prime}\left(c_{L}, h_{L}, w_{L}, \theta_{L}\right)}-K\left(\frac{U_{h}^{\prime}\left(c_{L}, h_{L}, w_{L}, \theta_{L}\right)}{U_{c}^{\prime}\left(c_{L}, h_{L}, w_{L}, \theta_{L}\right)}-\frac{U_{w}^{\prime}\left(c_{L}, h_{L}, w_{L}, \theta_{L}\right)}{U_{c}^{\prime}\left(c_{L}, h_{L}, w_{L}, \theta_{L}\right)} \frac{w_{L}}{h_{L}}\right) \\
=\frac{U_{h}^{\prime}\left(c_{L}, h_{L}, w_{L}, \theta_{H}\right)}{U_{w}^{\prime}\left(c_{L}, h_{L}, w_{L}, \theta_{H}\right)}
\end{array}
$$

with

$$
K=\frac{\gamma n_{L} h_{L} U_{c}^{\prime}\left(c_{L}, h_{L}, w_{L}, \theta_{L}\right)}{\beta U_{w}^{\prime}\left(c_{L}, h_{L}, w_{L}, \theta_{L}\right) U_{w}^{\prime}\left(c_{L}, h_{L}, w_{L}, \theta_{H}\right)}>0 .
$$

Combining equations (9) and (10), evaluated for the low ability type $L$, and using the definitions of $M C H$ and $M C W$, one finds

$$
\begin{aligned}
& T_{h}^{\prime}\left(h_{L}, w_{L}\right)=w_{L}+\frac{U_{h}^{\prime}\left(c_{L}, h_{L}, w_{L}, \theta_{L}\right)}{U_{c}^{\prime}\left(c_{L}, h_{L}, w_{L}, \theta_{L}\right)}, \\
& T_{w}^{\prime}\left(h_{L}, w_{L}\right)=h_{L}+\frac{U_{w}^{\prime}\left(c_{L}, h_{L}, w_{L}, \theta_{L}\right)}{U_{c}^{\prime}\left(c_{L}, h_{L}, w_{L}, \theta_{L}\right)},
\end{aligned}
$$


and thus

$T_{h}^{\prime}\left(h_{L}, w_{L}\right)-T_{w}^{\prime}\left(h_{L}, w_{L}\right) \frac{w_{L}}{h_{L}}=\frac{U_{h}^{\prime}\left(c_{L}, h_{L}, w_{L}, \theta_{L}\right)}{U_{c}^{\prime}\left(c_{L}, h_{L}, w_{L}, \theta_{L}\right)}-\frac{U_{w}^{\prime}\left(c_{L}, h_{L}, w_{L}, \theta_{L}\right)}{U_{c}^{\prime}\left(c_{L}, h_{L}, w_{L}, \theta_{L}\right)} \frac{w_{L}}{h_{L}}$.

Using equation (42) and the definition of $M W H$, equation (39) can be written as

$T_{h}^{\prime}\left(h_{L}, w_{L}\right)-T_{w}^{\prime}\left(h_{L}, w_{L}\right) \frac{w_{L}}{h_{L}}=\frac{1}{K}\left[M W H\left(c_{L}, h_{L}, w_{L}, \theta_{H}\right)-M W H\left(c_{L}, h_{L}, w_{L}, \theta_{L}\right)\right]$.

So, recalling Table 1, the sign of the earnings-conditional hours tax (the sign of the left-hand side) must coincide with the sign of $M W H_{\theta}^{\prime}$, and thus, given assumption B, it must be negative at the optimum (hence, proposition 7.1). 